\title{
Article \\ Effect of Isolation Conditions on Diversity of Endolichenic Fungal Communities from a Foliose Lichen, Parmotrema tinctorum
}

\author{
Ji Ho Yang ${ }^{1}$, Seung-Yoon Oh ${ }^{2} \mathbb{D}$, Wonyong Kim ${ }^{1} \mathbb{D}$, Jung-Jae Woo ${ }^{1}$, Hyeonjae Kim ${ }^{1}$ and Jae-Seoun Hur ${ }^{1, * \mathbb{D}}$ \\ 1 Korean Lichen Research Institute, Sunchon National University, 255 Jungang-Ro, Suncheon 57922, Korea; \\ 836019@naver.com (J.H.Y.); apbiomol@gmail.com (W.K.); wjdwoz@hanmail.net (J.-J.W.); \\ khj4173@hanmail.net (H.K.) \\ 2 Department of Biology and Chemistry, Changwon National University, 20 Changwondaehak-ro, \\ Changwon 51140, Korea; syoh@changwon.ac.kr \\ * Correspondence: jshur1@scnu.ac.kr; Tel.: +82-61-750-3383
}

Citation: Yang, J.H.; Oh, S.-Y.; Kim, W.; Woo, J.-J.; Kim, H.; Hur, J.-S. Effect of Isolation Conditions on Diversity of Endolichenic Fungal Communities from a Foliose Lichen, Parmotrema tinctorum. J. Fungi 2021, 7, 335. https://doi.org/10.3390/jof7050335

Academic Editors: Pradeep

K. Divakar and Raffaella Balestrini

Received: 15 March 2021

Accepted: 23 April 2021

Published: 26 April 2021

Publisher's Note: MDPI stays neutral with regard to jurisdictional claims in published maps and institutional affiliations.

Copyright: () 2021 by the authors. Licensee MDPI, Basel, Switzerland. This article is an open access article distributed under the terms and conditions of the Creative Commons Attribution (CC BY) license (https:// creativecommons.org/licenses/by/ $4.0 /)$.

\begin{abstract}
Endolichenic fungi (ELF) are emerging novel bioresources because their diverse secondary metabolites have a wide range of biological activities. Metagenomic analysis of lichen thalli demonstrated that the conventional isolation method of ELF covers a very limited range of ELF, and the development of an advanced isolation method is needed. The influence of four variables were investigated in this study to determine the suitable conditions for the isolation of more diverse ELF from a radially growing foliose lichen, Parmotrema tinctorum. Four variables were tested: age of the thallus, severity of surface-sterilization of the thallus, size of a thallus fragment for the inoculation, and nutrient requirement. In total, 104 species (1885 strains) of ELF were isolated from the five individual thalli of P. tinctorum collected at five different places. Most of the ELF isolates belong to Sordariomycetes. Because each part of lichen thallus (of different age) has unique ELF species, the whole thallus of the foliose lichen is needed to isolate diverse ELF. Moderate sterilization is appropriate for the isolation of diverse ELF. Inoculation of small fragment $\left(1 \mathrm{~mm}^{2}\right)$ of lichen thallus resulted in the isolation of highest diversity of ELF species compared to larger fragments (100 and $25 \mathrm{~mm}^{2}$ ). Moreover, ELF species isolated from the small thallus fragments covered all ELF taxa detected from the medium and the large fragments in this study. The use of two media-Bold's basal medium (nutrient poor) and potato dextrose agar (nutrient rich)—supported the isolation of diverse ELF. Among the tested variables, size of thallus fragment more significantly influenced the isolation of diverse ELF than other three factors. Species composition and richness of ELF communities from different lichen thalli differed from each other in this study.
\end{abstract}

Keywords: diversity; endolichenic fungi; foliose lichen; isolation method

\section{Introduction}

Lichens result from a symbiotic association between fungi and their photosynthetic partners [1], in which diverse microbial communities, including the endolichenic fungi (ELF), are housed. The ELF live inside the lichen thalli without any disease symptoms and are similar on their lifestyle to endophytic fungi $[2,3]$. They depend on photosynthesizing partner of lichen for their carbon source as heterotroph [4]. Therefore, ELF within the thallus of lichen are known to be abundantly located at the algal layer [3]. Taxonomic composition of ELF communities is distinct from that of endophytic fungal communities $[5,6]$. Several factors including type of host lichen, climate, and geographical region affect construction of ELF community [5-8]. Various ELF have a range of biological activities owing to their unique secondary metabolites. Novel natural products derived from ELF showed diverse bioactivities including antibacterial, antifungal, antioxidative, and cytotoxic effects [9-12]. Therefore, ELF are considered as novel and potential biological resources for pharmaceutical and biotechnological purposes. 
Metabarcoding results showed that there are highly diverse fungi in the lichen thallus [13]. Several studies have been performed in order to reveal the influence of different isolation conditions on the composition of culturable ELF communities. Muggia et al. reported the effects of different media on the community of isolated ELF [14]. Previous studies showed that the composition of isolated ELF was affected by different methods of sterilization of lichen surface $[15,16]$. Most of the studies focused only on the testing of a single factor of isolation conditions but not on their combined ability to increase the diversity of ELF. Therefore, more effort is needed to improve the conventional isolation conditions to explore novel ELF.

In this study, four isolation variables-thallus age, severity of surface sterilization, inoculum size, and type of medium-were tested to optimize isolation conditions ensuring the isolation of diverse ELF communities from a foliose lichen, Parmotrema tinctorum.

\section{Materials and Methods}

\subsection{Lichen Sampling}

Parmotrema tinctorum (Despr. ex Nyl.) Hale., a radially growing foliose macrolichen, was used as a model lichen species for the following reasons: it is distributed widely in the tropical and subtropical regions of the world [17,18]; it is loosely attached to the substrate so that the thallus can be peeled off easily and cleanly from the substrate, e.g., bark and rock; mature thallus of $P$. tinctorum has sufficient biomass for the test. Five individual lichen thalli were collected from the bark of pine trees (Pinus thunbergii Parl.) at five different sites of Jeju Island located at the subtropical zone of the southern part of South Korea. The climate of Jeju Island is affected by Southeast Asian monsoon [19]. Heavy rainfall derived from the East China Sea and the West Pacific contributes to high levels of humidity in summer. The climate during winter is characterized by cold and dry conditions. The mean annual temperature is around 25.4 and $5.1^{\circ} \mathrm{C}$ in summer and winter, respectively [20]. Five collection sites were the following: site $1\left(33^{\circ} 28^{\prime} 31^{\prime \prime} \mathrm{N}, 126^{\circ} 21^{\prime} 09^{\prime \prime} \mathrm{E}\right)$ is located at a seaside cliff and directly exposed to strong winds from the sea; site $2\left(33^{\circ} 30^{\prime} 28^{\prime \prime} \mathrm{N}, 126^{\circ} 28^{\prime} 01^{\prime \prime} \mathrm{E}\right)$ is a hill near the sea; site $3\left(33^{\circ} 32^{\prime} 59^{\prime \prime} \mathrm{N}, 126^{\circ} 45^{\prime} 26^{\prime \prime} \mathrm{E}\right)$ is located at the top of the rising small defunct volcano which has been used as a graveyard and surrounded by agricultural fields (citrus farms); site $4\left(33^{\circ} 14^{\prime} 1^{\prime \prime} \mathrm{N}, 126^{\circ} 22^{\prime} 59^{\prime \prime} \mathrm{E}\right)$ is located at a small park nearby the sea; and site $5\left(33^{\circ} 16^{\prime} 23^{\prime \prime} \mathrm{N}, 126^{\circ} 42^{\prime} 14^{\prime \prime} \mathrm{E}\right)$ is located along the seaside with densely-developed viridian forest (Figure 1a). 

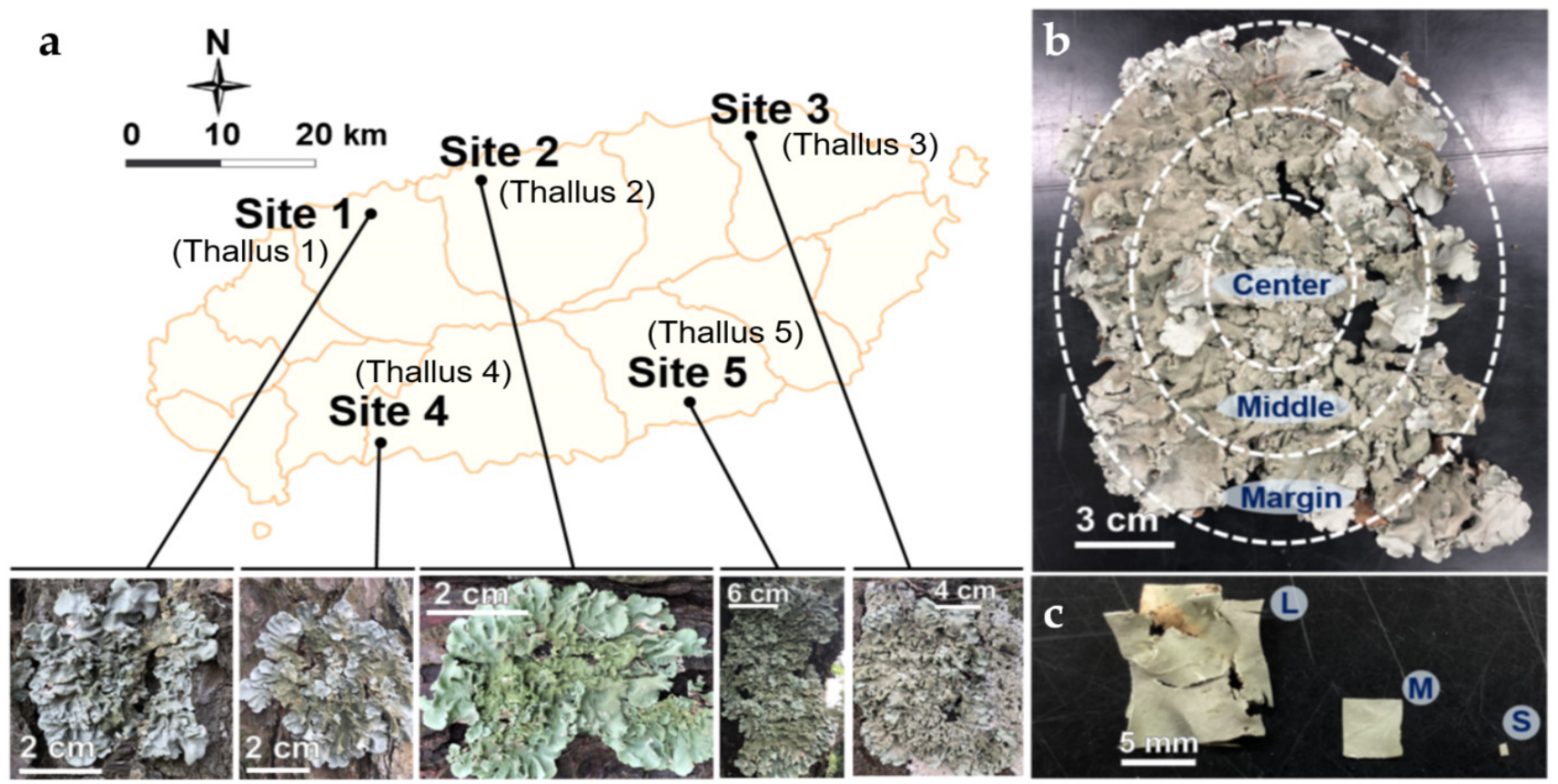

Figure 1. Collection sites and preparation of the thallus samples for ELF isolation. (a) Parmotrema tinctorum were collected from five sites in Jeju Island, South Korea; (b) Lichen thallus was divided into three parts by its diameter (center, middle and margin); (c) The piece of the lichen thallus was cut into three different sizes of inoculum (large: $100 \mathrm{~mm}^{2}$; medium: $25 \mathrm{~mm}^{2}$ and small: $1 \mathrm{~mm}^{2}$ ).

\subsection{Isolation of ELF: Modification of Four Variables}

ELF isolation was conducted based on the conventional methodology Figure S1 $[5,21]$. The residue (e.g., bark particles and web) on the lichen surface was removed physically using a syringe tip and running tap water. Lichen thallus was sterilized with ethanol and sodium hypochlorite $(\mathrm{NaOCl})$ and then cut to the required size (e.g., $\left.0.5 \mathrm{~cm}^{2}\right)[15,21]$. Finally, the sterilized thallus fragments were inoculated on a nutrient medium. Modification of the isolation conditions was attempted as follows. Each lichen thallus was divided into three parts (center, middle, and margin) by the diameter of thallus from center according to the age (older, old, and young) (Figure 1b). The lichen thallus was treated by different means of surface sterilization: $70 \%$ ethanol, followed by $0.4 \% \mathrm{NaOCl}$, during 60,90 , and $120 \mathrm{~s}$ (hereinafter referred to as mild, moderate, and severe, respectively), and then rinsed with sterilized distilled water (SDW) for $120 \mathrm{~s}$. The rinsed SDW was smeared on potato dextrose agar (PDA) to confirm the complete sterilization of the thallus surfaces. Sterilized thallus of three different parts was cut carefully into three different sizes of 100,25 , and $1 \mathrm{~mm}^{2}$ (hereinafter referred to as large, medium, and small, respectively) (Figure 1c). Large and medium thallus fragments were plated in 90-mm Petri dishes, four and six fragments per plate, respectively. Ten plates were inoculated with fragments of each size; altogether, 40 and 60 fragments of large and medium size, respectively, were incubated. Due to shortage of lichen thalli, only 2 thalli of $P$. tinctorum from site 3 and 5 were used to prepare large and medium thallus fragments. Four 24-well plates were inoculated with 24 pieces of the small fragments; altogether 96 small fragments were tested. The thallus fragments were inoculated on a media consisting of PDA, malt and yeast extract agar (MY, Difco, Spark, MD, USA) [22], Lysogeny broth (LB, Difco, Spark, MD, USA) [23], and Bold's basal medium (BBM) [24]. The fragments of medium size from the middle part of thallus were incubated on PDA after moderate sterilization as a control. The plates were incubated at room temperature (RT, ca. $21.5^{\circ} \mathrm{C}$ ) for more than 2 months. Newly growing mycelium was transferred to a fresh PDA for the pure culture. Pure isolates were incubated at $20^{\circ} \mathrm{C}$ until sufficient biomass for DNA extraction was obtained. 


\subsection{Molecular Identification}

The isolates were grouped into different morphotypes based on their morphological characteristics [25]. The genomic DNA (gDNA) of each morphotype was extracted using a PowerSoil DNA Isolation Kit (Qiagen, Hilden, Germany). The nuclear ribosomal internal transcribed spacer (ITS) region was amplified using the primers, ITS4 (TCCTCCGCTTATTGATATGC) and ITS5 (GGAAGTAAAAGTCGTAACAAGG) [26]. A polymerase chain reaction (PCR) was performed using PCR PreMix (Bioneer, Daejeon, Korea) in a final volume of $20 \mu \mathrm{L}$ containing $1 \mu \mathrm{L}$ of 10 pmol of bidirectional primer, $2 \mu \mathrm{L}$ of gDNA, and $16 \mu \mathrm{L}$ of SDW. The PCR conditions were as follows: $95^{\circ} \mathrm{C}$ for $5 \mathrm{~min}$, and 30 cycles of $94{ }^{\circ} \mathrm{C}$ for $30 \mathrm{~s}, 56^{\circ} \mathrm{C}$ for $30 \mathrm{~s}, 72{ }^{\circ} \mathrm{C}$ for $60 \mathrm{~s}$, and a final extension at $72{ }^{\circ} \mathrm{C}$ for $5 \mathrm{~min}$. The PCR product was checked using $1 \%$ agarose gel electrophoresis. Sequencing was accomplished using the GenoTech (Daejeon, Korea). The bidirectional sequences were edited, quality-checked using BioEdit ver. 7.0.5.3 (http:/ / www.mbio.ncsu.edu/BioEdit/bioedit.html, 1 March 2008) [27] and assembled using ATGC ver. 1.03 (GENETYX co, Tokyo, Japan). The whole sequences in this study were deposited in GenBank (Table S1). ITS sequence-based identification was conducted using BLAST against NCBI GenBank. Phylogenetic analysis was also conducted using the software MEGA ver. 7.0 (USA) [28] in the maximum-likelihood (ML) at the species level.

\subsection{Statistics and Visualization}

The phylogenetic trees were annotated and edited using the web-based tool, iTOL [29]. All statistical analyses were performed in $\mathrm{R}$ ver. 3.5.1 [30]. The rarefaction curve was constructed using the iNEXT package [31]. The isolate density was calculated by dividing the number of isolates by the number of segments of lichen thallus used: $n / 40$ (large), $n / 60$ (medium), and $n / 96$ (small) using the vegan package [32] and visualized using the ggplot2 package [33]. Isolate densities and species richness were compared using a Kruskal-Wallis test [34] followed by a Bonferroni correction [35] (multiple comparisons) and a Wilcoxon matched pairs test [36] (pairwise comparisons). Construction of the Venn diagrams was performed using the VennDiagram package [37]. Non-metric multidimensional scaling (NMDS) was set up using the vegan package based on the Bray-Curtis matrix [38].

\section{Results}

\subsection{Composition of ELF Biota}

Phylogenetic analysis showed that all the host samples belong to P. tinctorum (Figure S2). In total, 1885 strains were recovered from 5 thalli of $P$. tinctorum collected at different sites. As the depth of isolation almost reached the saturation point of the rarefaction curve, the sampling effort was sufficient to obtain the diverse species richness of the isolated ELF (Figure 2). After phylogenetic analysis, all the isolates were classified into 104 species, representing 2 phyla, 7 classes, 23 orders, 38 families, and 60 genera (Figure 3, Figure S3 and Table S1). 


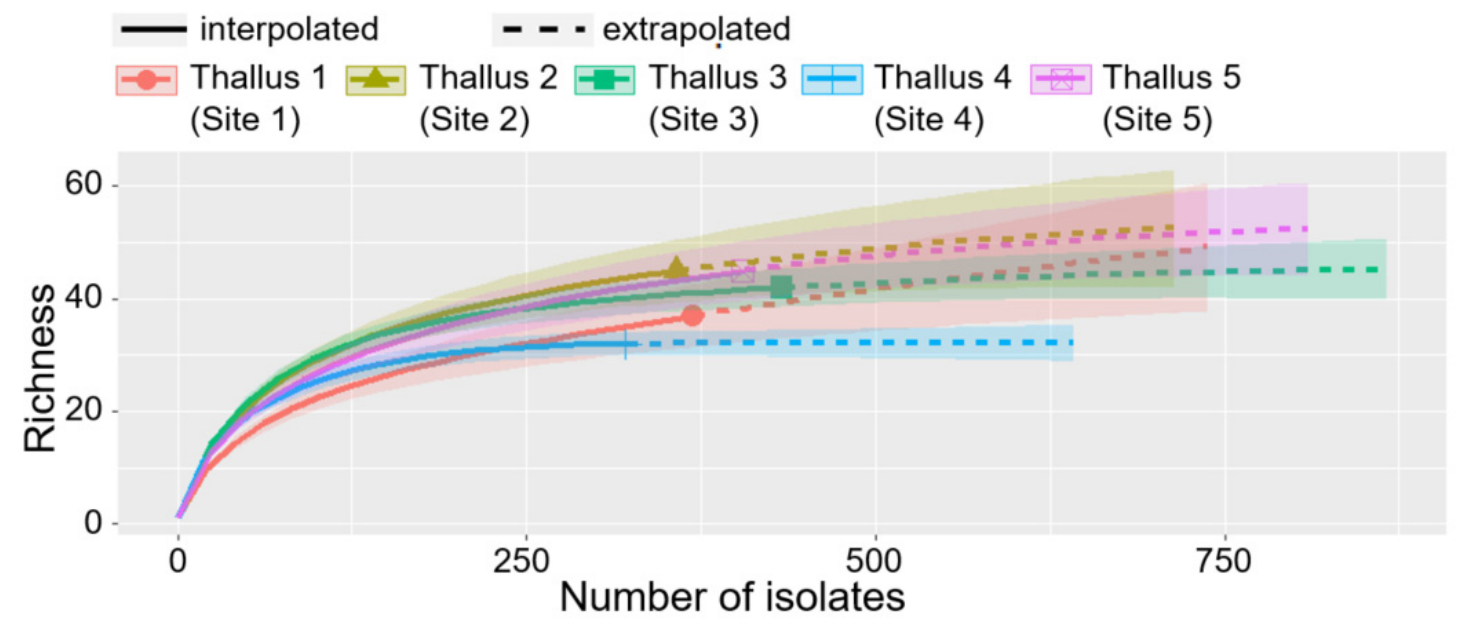

Figure 2. Rarefaction curves with $95 \%$ confidence intervals of estimated species richness of isolated ELF community.

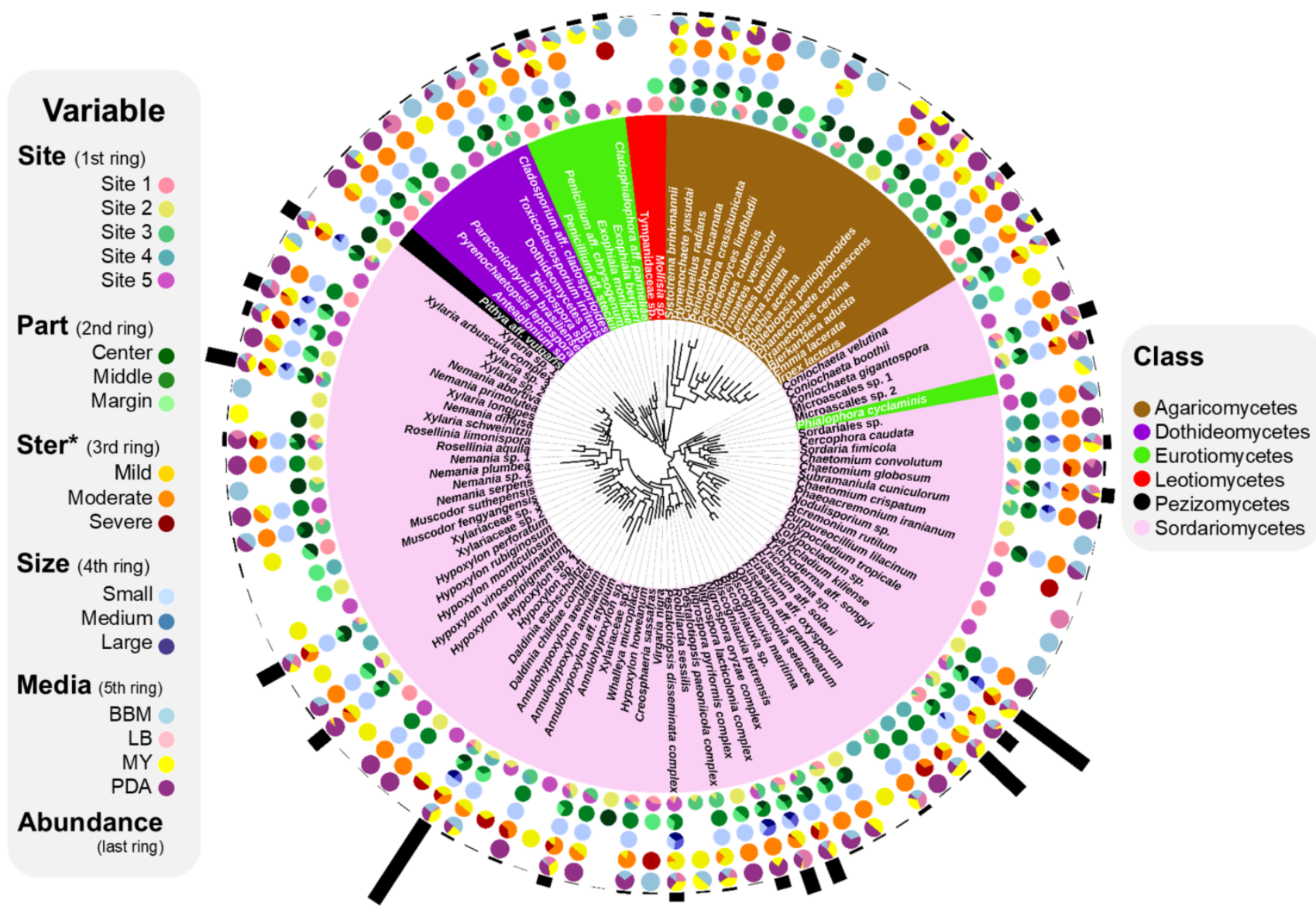

Figure 3. Phylogenetic relationships of the isolated ELF and relative abundances of classes in ELF communities isolated from different lichen thalli, different parts of lichen thallus, after different regimes of thallus surface sterilization, from fragments of different sizes and on different types of medium. Ster*, Sterilization.

Ascomycota was the dominant phylum (1736 isolates, 92.10\%). In Ascomycota, the most abundant class was Sordariomycetes (1618 isolates, $85.84 \%$ ), followed by Eurotiomycetes (73 isolates, $3.87 \%$ ) and Dothideomycetes (37 isolates, $1.96 \%$ ). At the order level, Xylariales ( 846 isolates, $44.88 \%$ ) was dominant, followed by Hypocreales (479 isolates, $25.41 \%$ ) and Trichosphaeriales (109 isolates, 5.78\%). At the family level, Xylariaceae ( 812 isolates, $43.08 \%$ ), Sarocladiaceae (248 isolates, $13.16 \%$ ), and Hypocreaceae (203 isolates, 
$10.77 \%$ ) were abundant. At the genus level, Daldinia ( 278 isolates, $14.75 \%$ ) was dominant, followed by Sarocladium (248 isolates, 13.16\%) and Trichoderma (203 isolates, 10.77\%). The most frequently isolated species was the Daldinia childiae complex (276 isolates, 14.64\%), followed by Sarocladium kiliense (248 isolates, $13.16 \%$ ) and Trichoderma sp. (152 isolates, $8.06 \%$ ). In Basidiomycota, 17 species were isolated. The most abundant species was Bjerkandera adusta (Phanerochaetaceae, Polyporales, 30 isolates, $1.59 \%$ ) followed by Irpex lacteus (Irpicaceae, Polyporales, 18 isolates, 0.95\%), Hymenochaete yasudai (Hymenochaetaceae, Hymenochaetales, 14 isolates, $0.74 \%$ ), and Trametes versicolor (Coriolaceae, Polyporales, 14 isolates, $0.74 \%$ ). The most abundant species, Daldinia childiae complex, was isolated from all study sites and under different isolation conditions (Figure 3). Some of the ELF belonging to Sordariomycetes (e.g., Sarocladium kiliense, Trichoderma sp., Coniochaeta veutina, Microasclaes spp., Nigrospora spp. and several species of Xylariaceae) were also isolated regardless of the isolation conditions. Several taxa were isolated only under specific isolation conditions.

\subsection{Effect of Isolation Conditions on Compositions of ELF Communities \\ 3.2.1. Effect of Size of Thallus Fragment on ELF Diversity}

The sizes of thallus fragment remarkably affected diversity of ELF communities. Isolate density (ID) and species richness were significantly different among the three different sizes of thallus fragment (Figure 4a,b). IDs of ELF communities from small, medium, and large part were $0.73 \pm 0.22,0.47 \pm 0.02$, and $0.66 \pm 0.06$, respectively $(n=2)$. The smaller the fragments that were used, the more diverse ELF were isolated. The highest species richness was observed in ELF community from small segment $(27.5 \pm 1.5, n=2)$, followed by that from medium $(8.5 \pm 0.5, n=2)$ and large segments $(7 \pm 1, n=2)$. Almost 4-times higher number of ELF species were recovered from small thallus fragment, compared to large thallus fragment (Figure $4 \mathrm{~b}$ ). As shown in Figure $5 \mathrm{a}$, use of small thallus fragment $\left(1 \mathrm{~mm}^{2}\right)$ covered all ELF taxa isolated from medium $\left(25 \mathrm{~mm}^{2}\right)$ and large $\left(100 \mathrm{~mm}^{2}\right)$ fragments. Notably, much more diverse ELF representing five classes (Agaricomycetes, Dothideomycetes, Eurotiomycetes, Pezizomycetes, and Sordariomycetes) were isolated from the small inoculum. Several orders of Sordariomycetes were isolated only from the medium and large inoculum (Table S2).

a

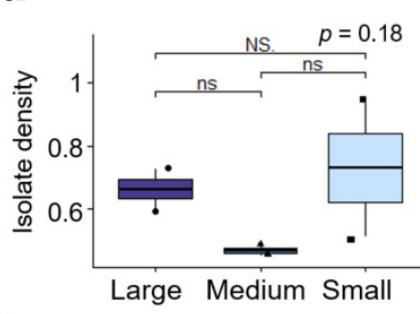

b

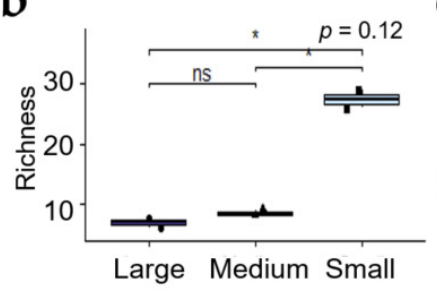

c
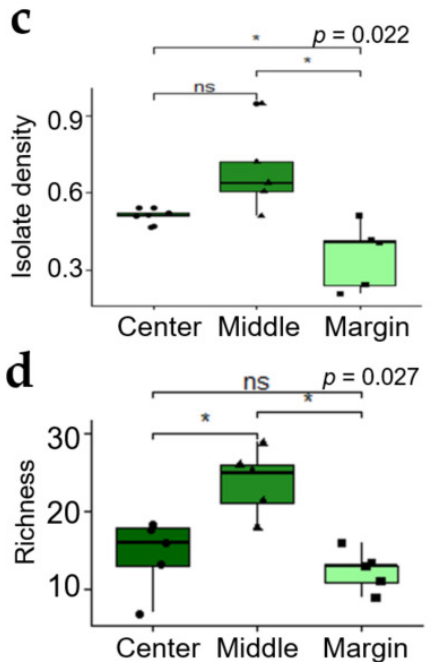

e

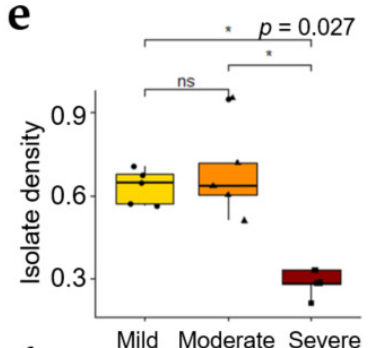

f

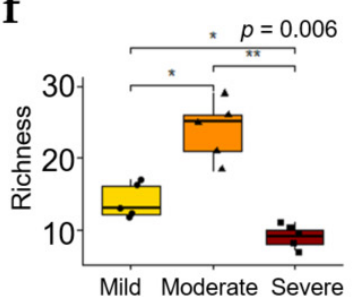

g

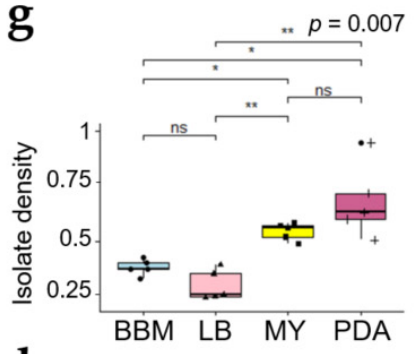

h

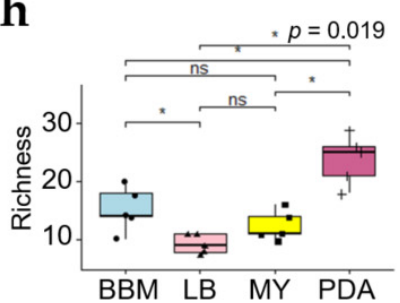

Figure 4. Isolate density and species richness of ELF communities from thallus fragments of different sizes $(\mathbf{a}, \mathbf{b})$, from different thallus parts $(\mathbf{c}, \mathbf{d})$, after different sterilization regimes $(\mathbf{e}, \mathbf{f})$, and on different media $(\mathbf{g}, \mathbf{h})$; Data of box plots are mean \pm s.d. $(n=5$, except for $(\mathbf{a}, \mathbf{b}) ; n=2) ;{ }^{* *} p<0.01,{ }^{*} p<0.05$. 

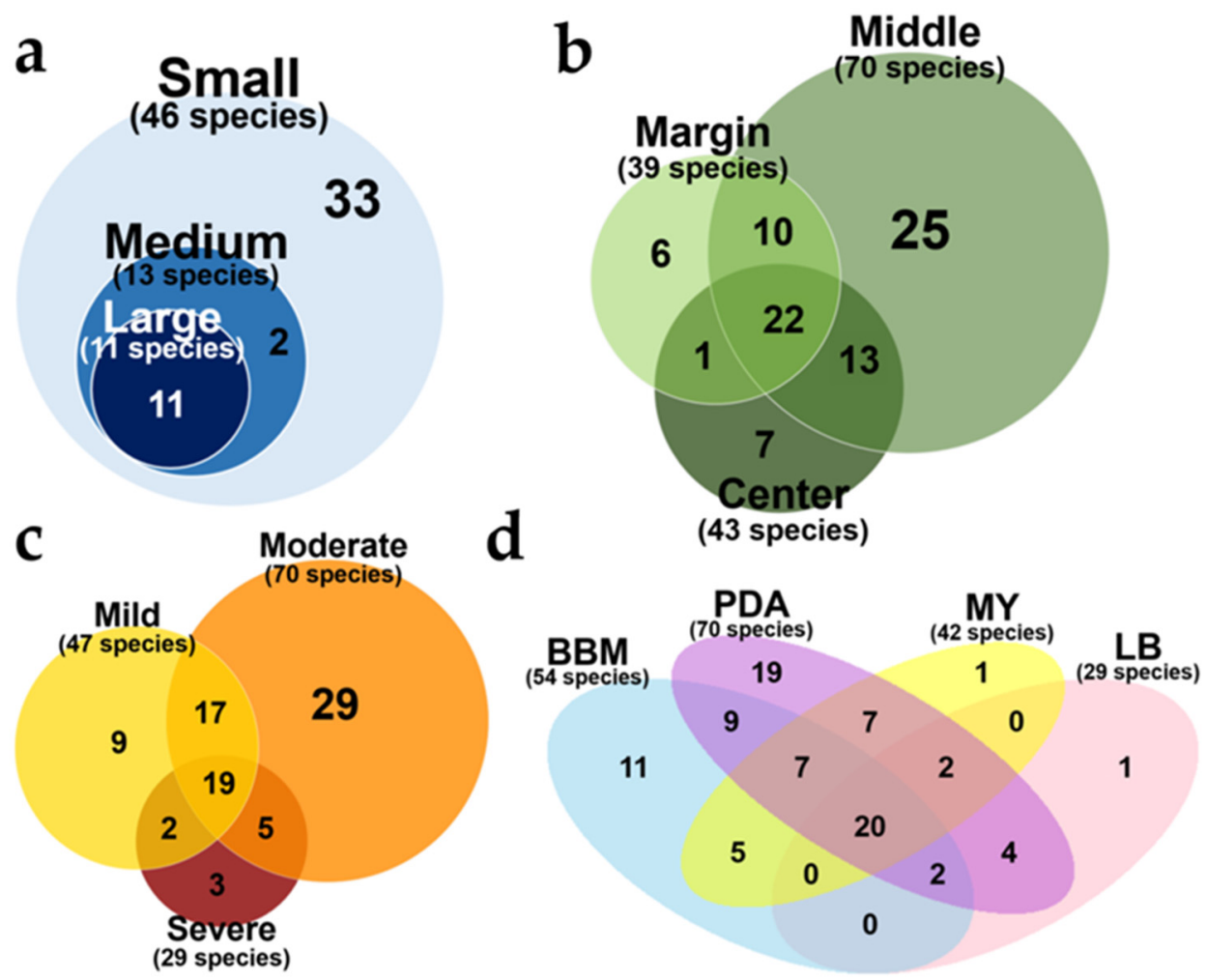

Figure 5. Venn diagrams showing relation among ELF communities from thallus fragments of different sizes (a), from different thallus parts (b), after different sterilization (c), and on different media (d).

\subsubsection{Effect of Thallus Age on the ELF Diversity}

Because the use of small thallus fragments gave the possibility to isolate all ELF taxa detected in the large and medium thallus fragments, we used small thallus fragment to evaluate effects of other isolation conditions on compositions of ELF communities. The ELF communities from different part of thallus representing different age showed a significant difference in ID (isolate density) (Kruskal-Wallis, $p<0.05$ ) (Figure $4 c$ ). The ELF communities from the old thallus of the middle part $(0.68 \pm 0.016, n=5)$ and the center part $(0.51 \pm 0.026, n=5)$ showed significantly higher IDs than that of the young thallus of the marginal part $(0.36 \pm 0.13, n=5)$ (Wilcoxon, $p<0.05)$. Species richness of the ELF communities isolated from different thallus parts were also significantly different (Kruskal-Wallis, $p<0.05$ ) (Figure $4 \mathrm{~d}$ ). The highest Richness was observed in the middle part of the lichen thallus $(23.80 \pm 4.32, n=5)$ followed by the center $(14.40 \pm 4.62, n=5)$ (Wilcoxon, $p<0.05)$, and marginal parts $(12.40 \pm 2.61, n=5)$ (Wilcoxon, $p<0.05)$. From the thallus fragments of all tested sizes, 70, 43, and 39 species were isolated from the middle, center, and marginal parts, respectively (Figure 5b). Notably, several specific taxa were isolated exclusively from each part of the lichen thallus. For example, Peniophora crassitunicata, Phlebia acerina, Paraconiothyrium brasiliense, Dothideomycetes sp., Penicillium aff. stecki, Sordariales sp. and Cercophora caudata were only isolated from the middle part. Cerrrena zonata, Cineromyces lindbladii, Hypoxylon howeanum, Lenzites betulinis, Nemania plumbea, Rosellinia limonispora, and Xylaria sp. 1 were detected only in the center part. Coniochaeta boothii, Mollisia sp., Muscodor fengyangensis, Trametes cubensis, Virgaria nigra, and Xylariaceae sp. 3 were solely isolated from the marginal part (Figure 3).

\subsubsection{Effect of Severity of Thallus Surface Sterilization on ELF Diversity}

IDs of ELF communities isolated after different regimes of surface sterilization differed significantly (Kruskal-Wallis, $p<0.05$ ) (Figure 4e). Severe sterilization significantly reduced the ID $(0.29 \pm 0.05, n=5)$ compared to mild $(0.63 \pm 0.064, n=5)$ and moderate sterilization 
$(0.68 \pm 0.17, n=5)$ (Wilcoxon, $p<0.05)$. The Richness was also significantly different after the three sterilization regimes. (Kruskal-Wallis, $p<0.01$ ) (Figure 4f). Moderate sterilization $(23.8 \pm 4.32, n=5)$ showed the highest Richness followed by mild (14 $\pm 2.34, n=5)$ (Wilcoxon, $p<0.05)$ and severe sterilization $(9 \pm 1.58, n=5)$ (Wilcoxon, $p<0.01)$. In particular, ELF belonging to Dothideomycetes were not isolated from the severely sterilized thallus (Table S2). From thallus fragments of all tested sizes, 47, 70 and 29 species were isolated after mild, moderate and severe sterilization of 5 lichen thalli, respectively (Figure $5 \mathrm{c}$ ). The growth of fungal hyphae was detected on PDA several days after inoculation of the rinsed SDW of the mild-sterilized thallus. On the other hand, no fungal hyphae growth was noted in the rinsed SDW of the moderate- and severe-sterilized thallus.

\subsubsection{Effect of the Medium Type on the ELF Diversity}

The IDs of ELF communities isolated on different media were remarkably different (Kruskal-Wallis, $p<0.01$ ) (Figure 4g). The IDs on BBM, LB, MY and PDA were $0.38( \pm 0.04$, $n=5), 0.3( \pm 0.07, n=5), 0.55( \pm 0.04, n=5)$ and $0.68( \pm 0.17, n=5)$, respectively. The IDs on PDA and MY were significantly higher than those on LB and BBM. The species richness of ELF on PDA $(23.8 \pm 4.32, n=5)$ was much higher than those on BBM $(15.2 \pm 3.90, n=5)$ Wilcoxon, $p<0.05)$, LB $(9.2 \pm 1.79, n=5)$ (Wilcoxon, $p<0.05)$, and MY $(12.4 \pm 2.50, n=5)$ (Wilcoxon, $p<0.05$ ) (Figure $4 \mathrm{~h}$ ). From thallus fragments of all tested sizes, 70, 54, 42 and 29 ELF species were recovered from PDA, BBM, MY and LB, respectively (Figure 5d). In particular, higher number of isolates of slow-growing fungi belonging to Chaetothyriales were recovered on BBM than on any other media (Table S2).

\subsection{Comparison of ELF Communities among Five Individual Lichen Thalli}

Diversity of ELF communities was also influenced by individual lichen samples collected at different sites (Figure 6 and Figure S4). Total species richness detected in each lichen varied from 32 (thallus 4 ) to 45 (thallus 5). Seven species belonging to Sordariomycertes such as Chaetomium globosum, Daldinia childiae complex, Hypoxylon perforatum, Microascales sp. 1, Nigrospora oryzae complex, Sarocladium kiliense, and Xylaria arbuscula complex were commonly isolated from all the tested five lichen samples. On the other hand, 9, 13, 5, 9, and 18 species were unique for each individual lichen inhabited at five sampling sites, respectively (Figure 6). 


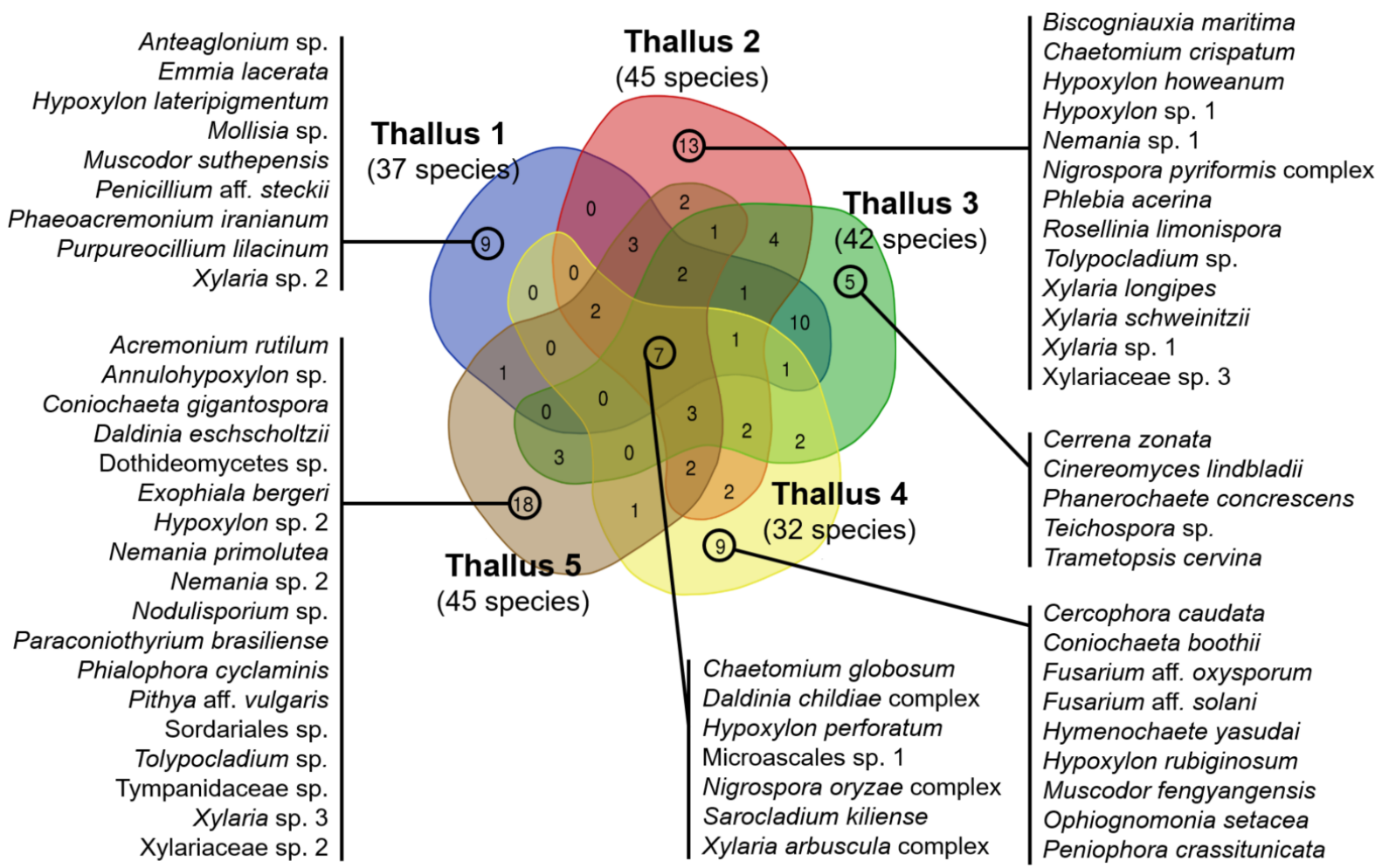

Figure 6. Composition of ELF communities isolated from five individual lichen thalli inhabited at 5 sampling sites. Lists of ELF from five individual lichen thalli represent unique species isolated from each lichen sample at each site.

\section{Discussion}

Our study showed that the diversity of the ELF communities can be affected by isolation conditions. Four variables were tested to optimize conditions for the isolation of diverse ELF communities from a foliose lichen. The middle part of thallus harbors more diverse ELF than the center and margin parts of thallus, but each part of thallus (different age of thallus) contained the unique ELF communities. The moderate sterilization of thallus surface can recover more diverse ELF communities without microbial contamination. Size of thallus fragments for inoculation seemed to be decisive to obtain most diverse ELF communities because smaller size can increase species richness by supporting slowgrowing fungal recovery from a pool of ELF. Type of medium is also considered to be important factor for increasing species richness and isolate density. For example, slowgrowing fungi were more frequently isolated on BBM than on any nutrient rich media.

Among four variables tested in this study, the sizes of thallus fragment was likely to be the most critical factor influencing species richness of ELF. In fact, use of small thallus fragment $\left(1 \mathrm{~mm}^{2}\right)$ covered all ELF taxa isolated from medium $\left(25 \mathrm{~mm}^{2}\right)$ and large $\left(100 \mathrm{~mm}^{2}\right)$ fragments. Previous studies normally used large fragments $\left(100\right.$ or $\left.25 \mathrm{~mm}^{2}\right)$ of sterilized thallus for ELF isolation. The small fragment $\left(1 \mathrm{~mm}^{2}\right)$ firstly tested in this study was found to be highly efficient for the isolation of diverse ELF communities, compared to large $\left(100 \mathrm{~mm}^{2}\right)$ or medium $\left(25 \mathrm{~mm}^{2}\right)$ thallus fragments normally used in conventional isolation methods.

Several studies observed Sordariomycetes-dominant patterns in ELF communities [8,15,39-41]. The most abundant species, Daldinia childiae complex, was isolated from all individual lichen samples and under all isolation conditions. D. childiae was recovered both from the branch of pine trees and lichen thalli $[42,43]$. D. childiae has been reported to be a putative saprobe that stays in fresh host-plant tissue without causing the disease symptoms for a long time [44]. Therefore, endolichenic $D$. childiae in this study might have originated from the bark of pine trees, a substrate of host lichen P. tinctorum. Sarocladium kiliense, another 
abundant species, was also known as an endophytic fungus in maze and lichen [16,45]. Unlike $S$. oryzae causing sheath blast in rice, S. kiliense was not reported as a pathogen. Trichoderma sp. was the third most frequent ELF species in this study. Rhizocompetent filamentous fungal group, Trichoderma spp., were found in various environments comprised of soil, plants, and lichens $[39,46,47]$. Those species produce biocontrol agents against plant pathogens $[47,48]$, but their enzymatic effects on lichen mycobiont are unclear. Therefore, Sordariomycetes species mentioned above are similar on their lifestyle to general endophytes and receive carbon inside the lichen thalli from the photobiont without causing pathogenic symptoms.

There were fungal species considered as specific or obligate occupants of the lichen thalli, e.g., lichenicolous fungi in previous studies $[49,50]$. The lichenicolous fungi were normally detectable only when they developed gall-like structures on lichen thalli. Lichenicolous fungus, Cladophialophora aff. parmeliae [51], was isolated in this study. Therefore, the modified method tested in this study recovered the known obligate fungal groups associated with the host lichen without the visible symptoms of gall-like structures [50]. Harutyunyan et al. had success in isolating of Cladophialophora sp. from healthy-looking thalli of Protoparmeliopsis muralis and Physcia dimidiata [52]. These findings agreed with the data obtained by metagenomic approach showing that several lichenicolous fungi might exist asymptomatically inside the lichen thallus [13].

Owing to the very slow growth rate of lichens, different parts of radially growing foliose lichen represent different ages of lichen thallus. Assuming that the growth rate of $P$. tinctorum is approximately $2 \mathrm{~cm}$ /year [53], the center, middle, and margin parts of the sample (thallus 3, for example) represent thalli of $6.25( \pm 1.25), 3.75( \pm 1.25)$, and 1.25 $( \pm 1.25)$ years old, respectively (Figure 1a). The ELF species of Mollisia sp., Coniochaeta boothii, and Muscodor fengyangensis, were uniquely isolated from the young marginal parts of the lichen thallus (Figure 3). Mollisia is a taxonomically neglected discomycete genus (Helotiales, Leotiomycetes) of saprotrophs commonly encountered on decaying plant tissues throughout the temperate regions [54]. Mollisa spp. were previously isolated from conifer needles. The endophytic Mollisia sp. may have alternatively colonized pine trees or the foliose lichen growing on the bark of the same pine tree. Coniochaeta species were present in several habitats such as plants, excrement, humus, and lichens $[55,56]$. Muscodor species are well-known endophytes that produce compounds lethal to pathogenic bacteria and fungi $[57,58]$. C. boothii and $M$. fengyangensis were reported as ELF for the first time.

In contrast to the young marginal part, the oldest central part of lichen thallus would harbor not only fungal species colonized from the early stage of the lichenization but also fungal groups recently colonized the thalli. Unlike higher plants, lichens lack a cuticle as a protective layer. To take water up from their surfaces, lichens are necessarily open systems, and for the same reason, most lichen-inhabiting fungi are not confined to the part of lichen thallus. Several species of Annulohypoxylon, Biscogniauxia, Hypoxylon, and Nigrospora were recovered from center, middle, and margin parts of the lichen thallus (Figure 3). These cosmopolitan genera are known as endophytes or facultative saprotrophs. Although the highest species richness of ELF was recorded in the middle part of the lichen thallus, the marginal part and central part still harbored their own unique ELF diversity of 6 and 7 species, respectively (Figure 5b). Therefore, several fragments of the whole lichen thallus from the center to the margins of foliose lichens should be used to isolate diverse ELF which can be undiscovered fungal taxa and may be potential novel bioresources for pharmacological purposes.

Because mild sterilization incompletely removed fungal contaminants from the surface of the lichen thallus, it was unsuitable for the isolation of ELF. Epiphytic fungal species isolated after mild sterilization of the lichen thallus might be regarded as saprobes, including the genera Annuloxypoxylon, Hypoxylon, and Muscodor (Figure 3) [59,60]. In contrast, severe sterilization significantly reduced the diversity of ELF, and possibly damaged the fungal tissues at the medulla underneath of thallus cortex. A lichenicolous species Cladophialophora aff. parmeliae was isolated under our stringent sterilization condition. This fungus was 
melanized in axenic cultures as other Cladophialophora species were [61]. This melanin accumulation may protect the fungus from the sterilization agent. Virgaria nigra was also recovered from the thallus fragments treated with severe surface sterilization (Figure 3). Virgaria spp. have been reported to be soil-borne and endophytes [62,63]. V. nigra was previously isolated from Peltigera dilacerata after sodium hypochlorite or hydrogen peroxide sterilization, but not after ethanol sterilization [16]. Moderate sterilization completely removed fungal contaminants from the thallus surface and recovered the highest species richness of the ELF. This suggests that moderate sterilization (70\% ethanol following $0.4 \%$ $\mathrm{NaOCl}$, each for $90 \mathrm{~s}$ ) can be applicable to isolating diverse ELF without interference from fungal saprobes on the thallus surface.

Previous studies normally used large fragments $\left(100\right.$ or $25 \mathrm{~mm}^{2}$ ) of sterilized thallus for ELF isolation. In our study, smaller fragments $\left(1 \mathrm{~mm}^{2}\right)$ were found to be more efficient for the isolation of diverse ELF by supporting slow-growing ELF recovery. When the largeand medium-sized thallus inocula (100 and $25 \mathrm{~mm}^{2}$ in this study) were tested, mainly fast-growing ELF species were detected in a few days. Once fast-growing fungi began to cover the surface of the medium, it was difficult to isolate slow-growing fungi [64]. The diversity of ELF species appeared to be negatively related to the size of thallus fragment. Slow-growing rhytismataceous fungi were difficult to isolate when large leaf disks were used in a previous study [65]. The use of tiny pieces of thallus inoculum $\left(1 \mathrm{~mm}^{2}\right)$ allowed to isolate more diverse ELF communities. As a result, slow-growing fungal taxa such as Pithya aff. vulgaris, Anteaglonium sp., Teichospora sp., Dothideomycetes sp., Cladophialophora aff. parmeliae, Tympanidaceae sp., Mollisia sp., and Microascales spp. were uniquely isolated from the small pieces of thallus. Apothecia of the cup fungus, Pithya spp. can be found on the bark or rock [66]. The species from the rare genus Anteaglonium are associated with decorticated wood [67,68]. Pithya aff. vulgaris and Anteaglonium sp. were first reported as endolichenic fungi of corticolous lichen.

The highest species richness of ELF was obtained on PDA, a common medium that supports growth of a variety of fungi [69]. The use of enrichment media, however, would allow fast-growing fungi to overgrow [70]. Thus, the use of at least two types of medium, enrichment medium for the growth of general fast-growing fungi and minimal medium for the isolation of slow-growing fungi, might ensure the isolation of fungal strains with different growth rates. The BBM was designed originally for the cultivation of green algae [71]. This carbon-deficient medium made it possible to isolate slow-growing fungi, including Cladophialophora aff. parmeliae, Teichospora sp., and Tympanidaceae sp. (Figure 3). Accordingly, Cladophialophora bantiana was previously isolated using sterilized mineral oil without a carbon source [72]. Therefore, the use of different nutrient media, such as BBM and PDA, would ensure the recovery of the broad spectrum of ELF from the lichen thalli.

\section{Conclusions}

The following conditions were applicable to isolating more diverse ELF: (1) use of whole thallus from the center to the margin of foliose lichens, (2) removal of surface fungal contaminants through the moderate sterilization of lichen thallus (70\% ethanol followed by $0.4 \% \mathrm{NaOCl}$, each for $90 \mathrm{~s}),(3)$ inoculation of tiny pieces $\left(1 \mathrm{~mm}^{2}\right)$ of sterilized thallus, and (4) the incubation of tiny pieces on two different types of nutrient medium: PDA (enriched medium) and BBM (minimal medium). Among the tested isolation conditions, the use of small fragments and different cultivation media apparently improved the efficiency of isolation of diverse and unexplored ELF from the lichen thallus. Diversity of ELF communities was also influenced by individual lichen samples collected at different sampling sites in our study.

Supplementary Materials: The following are available online at https://www.mdpi.com/article/10 .3390/jof7050335/s1, Figure S1: Schematic diagram of experimental design adopted for ELF isoaltion, Figure S2: Phylogenetic identification of host lichen Parmotrema tinctorum, Figure S3: Phylogenetic relationship of isolated ELF, Figure S4: NMDS ordination of isolated ELF community, Table S1: 
Taxonomic information of isolated ELF species, Table S2: Number of ELF species belonging to different orders in the ELF communities isolated from different isolation conditions.

Author Contributions: Conceptualization, J.H.Y. and J.-S.H.; methodology, J.H.Y. and J.-S.H.; validation, J.H.Y., S.-Y.O. and J.-S.H.; formal analysis, J.H.Y.; investigation, J.H.Y. and J.-J.W.; resources, J.-S.H.; data curation, J.H.Y., H.K. and S.-Y.O.; writing-original draft preparation, J.H.Y.; writingreview and editing, J.H.Y., S.-Y.O., W.K. and J.-S.H.; visualization, J.H.Y., H.K. and S.-Y.O.; supervision, J.-S.H.; project administration, J.-S.H.; funding acquisition, J.-S.H. All authors have read and agreed to the published version of the manuscript.

Funding: This work was supported by a grant from National Research Foundation of Korea (NRF2017M3A9B8069471, NRF-2018K1A3A1A13087249).

Institutional Review Board Statement: Not applicable.

Informed Consent Statement: Not applicable.

Data Availability Statement: The datasets are included within the article and Supplementary Material Files. Nucleotide sequences reported in this article are available via GenBank.

Conflicts of Interest: The authors declare no conflict of interest.

\section{References}

1. Ahmadjian, V. The Lichen Symbiosis; John Wiley \& Sons: Hoboken, NJ, USA, 1993.

2. Petrini, O. Fungal endophytes of tree leaves. In Microbial Ecology of Leaves; Springer: Berlin/Heidelberg, Germany, 1991; pp. 179-197.

3. Arnold, A.E.; Miadlikowska, J.; Higgins, K.L.; Sarvate, S.D.; Gugger, P.; Way, A.; Hofstetter, V.; Kauff, F.; Lutzoni, F.A. Phylogenetic estimation of trophic transition networks for ascomycetous fungi: Are lichens cradles of symbiotrophic fungal diversification? Syst. Biol. 2009, 58, 283-297. [CrossRef]

4. Suryanarayanan, T.S.; Thirunavukkarasu, N. Endolichenic fungi: The lesser known fungal associates of lichens. Mycology 2017, 8, 189-196. [CrossRef] [PubMed]

5. U’Ren, J.M.; Lutzoni, F.; Miadlikowska, J.; Arnold, A.E. Community analysis reveals close affinities between endophytic and endolichenic fungi in mosses and lichens. Microb. Ecol. 2010, 60, 340-353. [CrossRef]

6. U'Ren, J.M.; Lutzoni, F.; Miadlikowska, J.; Laetsch, A.D.; Arnold, A.E. Host and geographic structure of endophytic and endolichenic fungi at a continental scale. Am. J. Bot. 2012, 99, 898-914. [CrossRef] [PubMed]

7. Zhang, T.; Wei, X.-L.; Wei, Y.-Z.; Liu, H.-Y.; Yu, L.-Y. Diversity and distribution of cultured endolichenic fungi in the Ny-Ålesund Region, Svalbard (High Arctic). Extremophiles 2016, 20, 461-470. [CrossRef]

8. Oh, S.-Y.; Yang, J.H.; Woo, J.-J.; Oh, S.-O.; Hur, J.-S. Diversity and Distribution Patterns of Endolichenic Fungi in Jeju Island, South Korea. Sustainability 2020, 12, 3769. [CrossRef]

9. Wu, W.; Dai, H.; Bao, L.; Ren, B.; Lu, J.; Luo, Y.; Guo, L.; Zhang, L.; Liu, H. Isolation and structural elucidation of proline-containing cyclopentapeptides from an endolichenic Xylaria sp. J. Nat. Prod. 2011, 74, 1303-1308. [CrossRef]

10. Samanthi, K.; Wickramaarachchi, S.; Wijeratne, E.; Paranagama, P. Two new antioxidant active polyketides from Penicillium citrinum, an endolichenic fungus isolated from Parmotrema species in Sri Lanka. J. Natl. Sci. Found. Sri Lanka 2015, 42, 119-126. [CrossRef]

11. Li, G.; Wang, H.; Zhu, R.; Sun, L.; Wang, L.; Li, M.; Li, Y.; Liu, Y.; Zhao, Z.; Lou, H. Phaeosphaerins A-F, cytotoxic perylenequinones from an endolichenic fungus, Phaeosphaeria sp. J. Nat. Prod. 2012, 75, 142-147. [CrossRef]

12. Ding, G.; Li, Y.; Fu, S.; Liu, S.; Wei, J.; Che, Y. Ambuic acid and torreyanic acid derivatives from the endolichenic fungus Pestalotiopsis sp. J. Nat. Prod. 2008, 72, 182-186. [CrossRef]

13. Fernández-Mendoza, F.; Fleischhacker, A.; Kopun, T.; Grube, M.; Muggia, L. ITS1 metabarcoding highlights low specificity of lichen mycobiomes at a local scale. Mol. Ecol. 2017, 26, 4811-4830. [CrossRef] [PubMed]

14. Muggia, L.; Kopun, T.; Grube, M. Effects of Growth Media on the Diversity of Culturable Fungi from Lichens. Molecules 2017, 22, 824. [CrossRef] [PubMed]

15. Suryanarayanan, T.; Thirunavukkarasu, N.; Hariharan, G.; Balaji, P. Occurrence of non-obligate microfungi inside lichen thalli. Sydowia-Horn- 2005, 57, 120.

16. Masumoto, H.; Degawa, Y. The effect of surface sterilization and the type of sterilizer on the genus composition of lichen-inhabiting fungi with notes on some frequently isolated genera. Mycoscience 2019, 60, 331-342. [CrossRef]

17. Gomes, A.T.; Honda, N.K.; Roese, F.M.; Muzzi, R.M.; Marques, M.R. Bioactive derivatives obtained from lecanoric acid, a constituent of the lichen Parmotrema tinctorum (Nyl.) Hale (Parmeliaceae). Rev. Bras. De Farmacogn. 2002, 12, 74-75. [CrossRef]

18. Jayalal, U.; Divakar, P.K.; Joshi, S.; Oh, S.-O.; Koh, Y.J.; Hur, J.-S. The Lichen Genus Parmotrema in South Korea. Mycobiology 2013, 41, 25-36. [CrossRef] [PubMed]

19. Bae, J.; Nam, S. An analysis of the effect of climate indicators on tourism demand: A case study of Jeju Island. J. Policy Res. Tour. Leis. Events 2020, 12, 185-196. [CrossRef] 
20. Won, J.-H.; Lee, J.-Y.; Kim, J.-W.; Koh, G.-W. Groundwater occurrence on Jeju Island, Korea. Hydrogeol. J. 2006, 14, 532-547. [CrossRef]

21. Li, W.-C.; Zhou, J.; Guo, S.-Y.; Guo, L.-D. Endophytic fungi associated with lichens in Baihua mountain of Beijing, China. Fungal Divers 2007, 25, 69-80.

22. Andreasen, A.A.; Stier, T. Anaerobic nutrition of Saccharomyces cerevisiae. I. Ergosterol requirement for growth in a defined medium. J. Cell. Comp. Physiol. 1953, 41, 23-36. [CrossRef] [PubMed]

23. Lwoff, A. Lysogeny. Bacteriol. Rev. 1953, 17, 269-337. [CrossRef] [PubMed]

24. Bold, H.C. The morphology of Chlamydomonas chlamydogama, sp. nov. Bull. Torrey Botanical Club. 1949, 101-108. [CrossRef]

25. Lacap, D.; Hyde, K.; Liew, E. An evaluation of the fungal'morphotype'concept based on ribosomal DNA sequences. Fungal Divers. 2003, 12, 53-66.

26. White, T.J.; Bruns, T.; Lee, S.; Taylor, J. Amplification and direct sequencing of fungal ribosomal RNA genes for phylogenetics PCR Protoc. Guide Methods Appl. 1990, 18, 315-322.

27. Hall, T. BioEdit Version 7.0.0. 2004. Available online: www.mbio.ncsu.edu/BioEdit/bioedit.html (accessed on 1 March 2008).

28. Kumar, S.; Stecher, G.; Tamura, K. MEGA7: Molecular evolutionary genetics analysis version 7.0 for bigger datasets. Mol. Biol. Evol. 2016, 33, 1870-1874. [CrossRef] [PubMed]

29. Letunic, I.; Bork, P. Interactive Tree Of Life (iTOL): An online tool for phylogenetic tree display and annotation. Bioinformatics 2007, 23, 127-128. [CrossRef] [PubMed]

30. R Core Team. R: A Language and Environment for Statistical Computing; R Core Team: Vienna, Austria, 2013.

31. Hsieh, T.; Ma, K.; Chao, A. iNEXT: An R package for rarefaction and extrapolation of species diversity (H ill numbers). Methods Ecol. Evol. 2016, 7, 1451-1456. [CrossRef]

32. Oksanen, J.; Blanchet, F.G.; Kindt, R.; Legendre, P.; O’hara, R.; Simpson, G.L.; Solymos, P.; Stevens, M.H.H.; Wagner, H. Vegan: Community Ecology Package. R Package Version 1.17-4. 2010. Available online: https://cran.r-project.org/web/packages/ vegan/index.html (accessed on 1 January 2011).

33. Wickham, H. ggplot2: Elegant Graphics for Data Analysis; Springer: Berlin/Heidelberg, Germany, 2016.

34. Breslow, N. A generalized Kruskal-Wallis test for comparing K samples subject to unequal patterns of censorship. Biometrika 1970, 57, 579-594. [CrossRef]

35. Armstrong, R.A. When to use the B onferroni correction. Ophthalmic Physiol. Opt. 2014, 34, 502-508. [CrossRef]

36. Gehan, E.A. A generalized Wilcoxon test for comparing arbitrarily singly-censored samples. Biometrika 1965, 52, 203-224. [CrossRef]

37. Chen, H.; Boutros, P.C. VennDiagram: A package for the generation of highly-customizable Venn and Euler diagrams in R. BMC Bioinform. 2011, 12, 35. [CrossRef]

38. Legendre, P.; Borcard, D.; Peres-Neto, P.R. Analyzing beta diversity: Partitioning the spatial variation of community composition data. Ecol. Monogr. 2005, 75, 435-450. [CrossRef]

39. Suryanarayanan, T.S.; Govindarajulu, M.; Rajamani, T.; Tripathi, M.; Joshi, Y. Endolichenic fungi in lichens of Champawat district, Uttarakhand, northern India. Mycol. Prog. 2017, 16, 205-211. [CrossRef]

40. Vinayaka, K.; Krishnamurthy, Y.; Banakar, S.; Kekuda, T.P. Association and variation of endophytic fungi among some macrolichens in central Western Ghats, Southern India. Int. J. Curr. Microbiol. Appl. Sci. 2016, 5, 115-124. [CrossRef]

41. Rajulu, M.B.G.; Thirunavukkarasu, N.; Kumar, S.S.; Kaur, T.; Reddy, M.S.; Suryanarayanan, T.S. Endolichenic fungal diversity associated with some lichens of the Western Ghats. Planta Med. 2020, 86, 960-966. [CrossRef]

42. Nguyen, M.H.; Yong, J.H.; Sung, H.J.; Lee, J.K. Screening of Endophytic Fungal Isolates against Raffaelea quercus-mongolicae Causing Oak Wilt Disease in Korea. Mycobiology 2020, 48, 484-494. [CrossRef] [PubMed]

43. Zhou, X.; Yang, C.; Meng, Q.; Liu, L.; Fu, S. A new alkanol from the endolichenic fungus Daldinia childiae. J. Chin. Chem. Soc. 2020, 68,678681 .

44. Stadler, M.; Læssøe, T.; Fournier, J.; Decock, C.; Schmieschek, B.; Tichy, H.-V.; Peršoh, D. A polyphasic taxonomy of Daldinia (Xylariaceae). Stud. Mycology 2014, 77, 1-143. [CrossRef] [PubMed]

45. Giraldo, A.; Gené, J.; Sutton, D.; Madrid, H.; De Hoog, G.; Cano, J.; Decock, C.; Crous, P.W.; Guarro, J. Phylogeny of Sarocladium (Hypocreales). Persoonia: Mol. Phylogeny Evol. Fungi 2015, 34, 10. [CrossRef]

46. Elad, Y.; Chet, I.; Henis, Y. A selective medium for improving quantitative isolation of Trichoderma spp. from soil. Phytoparasitica 1981, 9, 59-67. [CrossRef]

47. Papavizas, G. Trichoderma and Gliocladium: Biology, ecology, and potential for biocontrol. Annu. Rev. Phytopathol. 1985, $23,23-54$. [CrossRef]

48. Reino, J.L.; Guerrero, R.F.; Hernández-Galán, R.; Collado, I.G. Secondary metabolites from species of the biocontrol agent Trichoderma. Phytochem. Rev. 2008, 7, 89-123. [CrossRef]

49. Kondratyuk, S.; Lőkös, L.; Halda, J.; Haji Moniri, M.; Farkas, E.; Park, J.; Mishra, G.K.; Nayaka, S.; Farkas, E.; Park, J.S.; et al. New and noteworthy lichen-forming and lichenicolous fungi 4. Acta Bot. Hung. 2016, 58, 75-136. [CrossRef]

50. Lawrey, J.D.; Diederich, P. Lichenicolous fungi: Interactions, evolution, and biodiversity. Bryologist 2003, 106, 80-120. [CrossRef]

51. Diederich, P.; Lawrey, J.D.; Ertz, D. The 2018 classification and checklist of lichenicolous fungi, with 2000 non-lichenized, obligately lichenicolous taxa. Bryologist 2018, 121, 340-426. [CrossRef] 
52. Harutyunyan, S.; Muggia, L.; Grube, M. Black fungi in lichens from seasonally arid habitats. Stud. Mycol. 2008, 61, 83-90. [CrossRef] [PubMed]

53. Boonpeng, C.; Polyiam, W.; Sriviboon, C.; Sangiamdee, D.; Watthana, S.; Nimis, P.L.; Boonpragob, K. Airborne trace elements near a petrochemical industrial complex in Thailand assessed by the lichen Parmotrema tinctorum (Despr. ex Nyl.) Hale. Environ. Sci. Pollut. Res. 2017, 24, 12393-12404. [CrossRef] [PubMed]

54. Tanney, J.; Seifert, K. Mollisiaceae: An overlooked lineage of diverse endophytes. Stud. Mycol. 2020, 95, 293-380. [CrossRef]

55. Checa, J.; Barrasa, J.; Moreno, G.; Fort, F.; Guarro, J. The genus Coniochaeta (Sacc.) Cooke (Coniochaetaceae, Ascomycotina) in Spain. Cryptog. Mycol. 1988, 9, 1-34.

56. Wang, Y.; Zheng, Z.; Liu, S.; Zhang, H.; Li, E.; Guo, L.; Che, Y. Oxepinochromenones, furochromenone, and their putative precursors from the endolichenic fungus Coniochaeta sp. J. Nat. Prod. 2010, 73, 920-924. [CrossRef]

57. Ezra, D.; Hess, W.; Strobel, G.A. New endophytic isolates of Muscodor albus, a volatile-antibiotic-producing fungus. Microbiology 2004, 150, 4023-4031. [CrossRef]

58. Mitchell, A.M.; Strobel, G.A.; Moore, E.; Robison, R.; Sears, J. Volatile antimicrobials from Muscodor crispans, a novel endophytic fungus. Microbiology 2009, 156, 270-277. [CrossRef] [PubMed]

59. Miller, J.H. A Monograph of the World Species of Hypoxylon; University of Georgia Press: Athens, GA, USA, 1961.

60. Sánchez-Ballesteros, J.; González, V.; Salazar, O.; Acero, J.; Portal, M.A.; Julián, M.; Rubio, V.; Bills, G.F.; Polishook, J.D.; Platas, G.; et al. Phylogenetic study of Hypoxylon and related genera based on ribosomal ITS sequences. Mycologia 2000, 92, 964-977. [CrossRef]

61. Badali, H.; Gueidan, C.; Najafzadeh, M.; Bonifaz, A.; van den Ende, A.G.; De Hoog, G. Biodiversity of the genus Cladophialophora. Stud. Mycol. 2008, 61, 175-191. [CrossRef] [PubMed]

62. Nonaka, K.; Ishii, T.; Shiomi, K.; Ōmura, S.; Masuma, R. Virgaria boninensis, a new hyphomycete (Xylariaceae) from soils in the Bonin Islands, Japan. Mycoscience 2013, 54, 394-399. [CrossRef]

63. Evans, H.C.; Holmes, K.A.; Thomas, S.E. Endophytes and mycoparasites associated with an indigenous forest tree, Theobroma gileri, in Ecuador and a preliminary assessment of their potential as biocontrol agents of cocoa diseases. Mycol. Prog. 2003, 2, 149-160. [CrossRef]

64. Morrison-Gardiner, S. Dominant fungi from Australian coral reefs. Fungal Divers 2002, 9, 105-121.

65. Osono, T. Endophytic and epiphytic phyllosphere fungi of Camellia japonica: Seasonal and leaf age-dependent variations. Mycologia 2008, 100, 387-391. [CrossRef] [PubMed]

66. Wu, M.-L. Two Pezizales from Taiwan. TAIWANIA-TAIPEI- 2001, 46, 238-245.

67. Jayasiri, S.C.; Jones, E.G.; Kang, J.-C.; Promputtha, I.; Bahkali, A.H.; Hyde, K.D. A new species of genus Anteaglonium (Anteagloniaceae, Pleosporales) with its asexual morph. Phytotaxa 2016, 263, 233-244. [CrossRef]

68. Jaklitsch, W.M.; Fournier, J.; Voglmayr, H. Two unusual new species of Pleosporales: Anteaglonium rubescens and Atrocalyx asturiensis. Sydowia 2018, 70, 129. [PubMed]

69. Bills, G.F.; Foster, M.S. Formulae for selected materials used to isolate and study fungi and fungal allies. In Biodiversity of Fungi: Inventory and Monitoring Methods; Academic Press: Cambridge, MA, USA, 2004; pp. 595-618.

70. Madrid, H.; Hernandez-Restrepo, M.; Gené, J.; Cano, J.; Guarro, J.; Silva, V. New and interesting chaetothyrialean fungi from Spain. Mycol. Prog. 2016, 151, 179-201. [CrossRef]

71. Ilavarasi, A.; Mubarakali, D.; Praveenkumar, R.; Baldev, E.; Thajuddin, N. Optimization of various growth media to freshwater microalgae for biomass production. Biotechnology 2011, 10, 540-545. [CrossRef]

72. Vicente, V.; Attili-Angelis, D.; Pie, M.; Queiroz-Telles, F.; Cruz, L.; Najafzadeh, M.J.; De Hoog, G.S.; Zhao, J.; Pizzirani-Kleiner, A. Environmental isolation of black yeast-like fungi involved in human infection. Stud. Mycol. 2008, 61, 137-144. [CrossRef] [PubMed] 